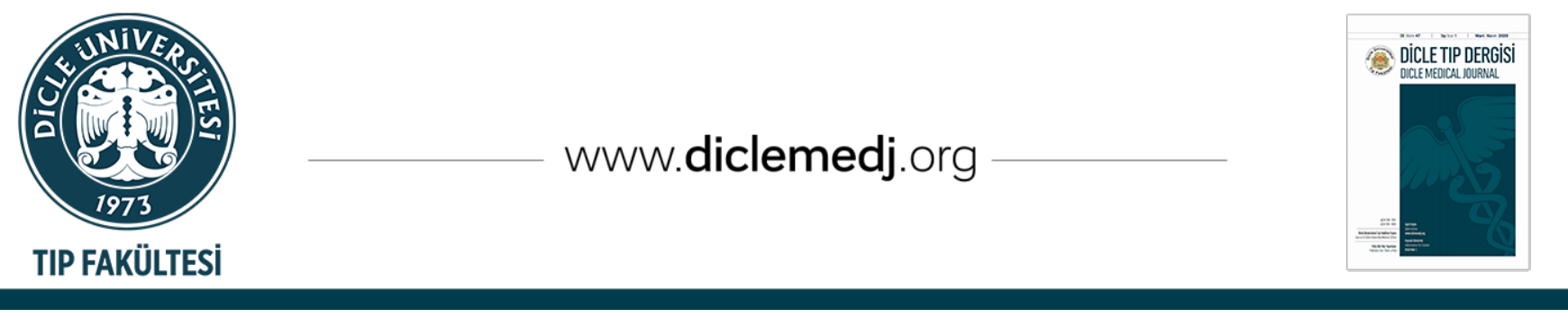

\title{
Graves Olgularında Kardiyovasküler Hastalık Risk Değerlendirmesi: Trombosit İndekslerinin Rolü
}

\author{
Hakim Çelik iD 1, Seyhan Taşkın (iD 1, Adnan Kirmit iD 2, Mehmet Ali Eren (D) 3 \\ 1 Harran Üniversitesi, Tıp Fakültesi, Fizyoloji Anabilim Dalı Şanlıurfa, Türkiye \\ 2 Harran Üniversitesi, Tıp Fakültesi, Tıbbi Biyokimya Anabilim Dalı Şanlıurfa, Türkiye \\ 3 Harran Üniversitesi, Tıp Fakültesi, Endokrinoloji Bilim Dalı Şanlıurfa, Türkiye
}

Geliş: 10.03.2020; Revizyon: 02.09.2020; Kabul Tarihi: 07.09.2020

Öz

Amaç: Gelişmiş ülkelerde en sık görülen hipertiroidi nedeni olarak belirtilen Graves hastalığı, tirotoksikoz, diffüz guatr ve oftalmopati ile karakterize otoimmün bir hastalıktır. Tiroid hormonunun, kardiyovasküler hemodinamiği değiștirebilecek etkilere sahip olması, hipertroidili hastaların kardiyovasküler komplikasyonlara yakalanma riskini arttırmaktadır. Tam kan sayımında rutin olarak rapor edilen; ortalama trombosit hacmi başta olmak üzere, trombosit indeksleri kardiyovasküler hastalıkların gelişimi ve takibinde önemli biyobelirteçler olarak kabul edilmektedir. Bu nedenle çalışmamızda Graves hastalığının kardiyovasküler hastalıklar ile ilișkisini değerlendirebilmek amacıyla trombosit indekslerinin rolü araştırıldı.

Yöntemler: Çalışmaya 33 Graves hipertiroidili hasta ile cinsiyet, yaş ve vücut kitle indeksi benzer 37 sağlıklı kontrol dahil edildi. Çalışmada rutin olarak ölçülmüş olan trombosit indeksleri ve tiroid fonksiyon parametreleri incelendi.

Bulgular: Graves hastaları ile kontrol grupları arasında trombosit sayısı ve trombosit yüzdesi bakımından anlamlı herhangi bir fark bulunmazken (sırasıyla; $p=0,202 ; p=0,289$ ), ortalama trombosit hacmi ve trombosit dağılım genişliği Graves hastalarında kontrol grubuna göre anlamlı ölçüde yüksek bulundu (sırasıyla; $p<0,001 ; p=0,015$ ). Ayrıca Graves hastalarında ortalama trombosit hacmi ve trombosit dağılım genişliği ile serbest triiyodotironin arasında anlamlı pozitif ilişki saptanmıştır (sırasıyla; $r=0,505 ; p=0,003$ ve $r=$ 0,366; $p=0,036$ ). Yapılan alıcı işletim karakteristiği (ROC) analizine göre Graves hastalarında, ortalama trombosit hacmi ve trombosit dağılım genişliği düzeylerinin kardiyovasküler hastalıkların risk değerlendirilmesi için kabul edilebilir bir prediktif değere sahip olduğu gösterilmiştir.

Sonuç: Sonuç olarak, Graves hastalarında kardiyovasküler hastalıkları öngörebilecek önemli biyobelirteçler olduğu düşünülen ortalama trombosit hacmi ve trombosit dağılım genişliği yüksek bulunmuştur. Bu durum Graves hastalarının kardiyovasküler hastalıklara yakalanma riskinin yüksek olabileceğini düşündürmektedir.

Anahtar kelimeler: Graves hastalığı, Trombosit indeksleri, Kardiyovasküler hastalıklar

DOI: $10.5798 /$ dicletip.800294

Correspondence / Yazışma Adresi: Hakim Çelik, Harran Üniversitesi Tıp Fakültesi Fizyoloji Anabilim Dalı Haliliye/Şanlıurfa, Türkiye email: hakimcell@gmail.com 


\title{
Cardiovascular Disease Risk Assessment in Graves' Cases: The Role of Platelet Indices
}

\begin{abstract}
Objective: Graves' disease, which is the most common cause of hyperthyroidism in developed countries, is an autoimmune disease characterized by thyrotoxicosis, diffuse goiter and ophthalmopathy. The fact that thyroid hormone has effects that can change cardiovascular hemodynamics increases the risk of cardiovascular complications in patients with hyperthyroidism. Platelet indices, especially mean platelet volume routinely reported in whole blood count are considered as important biomarkers for the development and follow-up of cardiovascular diseases. Therefore, in this study, we investigated the role of platelet indices in order to evaluate the relationship between Graves' disease and cardiovascular diseases.
\end{abstract}

Methods: Thirty-three patients with Graves' hyperthyroidism and 37 healthy controls with similar sex, age and body mass index were included in the study. In this study, platelet indices and thyroid function parameters routinely measured were evaluated.

Results: There was no significant difference in platelet count and platelet percentage between Graves patients and control groups ( $\mathrm{p}=$ $0.202 ; p=0.289$, respectively), whereas mean platelet volume and platelet distribution width were significantly higher in Graves patients compared to control group $(\mathrm{p}<0.001 ; \mathrm{p}=0.015$, respectively). In addition, a significant positive correlation was found between mean platelet volume and platelet distribution width and free triiodothyronine in Graves' patients ( $\mathrm{r}=0.505 ; \mathrm{p}=0.003$ and $\mathrm{r}=0.366$; $\mathrm{p}=0.036$, respectively). According to Receiver operating characteristic (ROC) analysis, mean platelet volume and platelet distribution width levels have an acceptable predictive value for cardiovascular diseases risk assessment in Graves' patients.

Conclusion: Our results showed that mean platelet volume and platelet distribution width are important biomarkers that may predicting cardiovascular diseases in Graves 'disease. Therefore, in this study platelet indices suggest that Graves' patients may have a high risk of developing cardiovascular diseases.

Keywords: Graves' Disease, Platelet indices, Cardiovascular Diseases.

\section{GíRiş}

Graves hastalığg, tiroid bezindeki tiroid uyarıcı hormon reseptörüne bağlanan otoantikorlar nedeniyle hipertiroidizme neden olan otoimmün temelli bir hastalıktır ${ }^{1}$. Graves hastalığının birçok karakteristik belirtileri ve semptomlarl, tiroid hormon seviyelerinin yükselmesinden kaynaklanmaktadır. Oftalmopati, dermopati ve akropati ile karakterize olan bu hastalığın klinik belirtileri arasında çarpıntı, ısı intoleransı, kilo kaybı ve anksiyete sayılabilir ${ }^{2,3}$. Özellikle 30-50 yaşları arasında insidansı yüksek olan bu hastalığa yakalanma riski kadınlarda, sigara içenlerde ve diğer otoimmün hastalıkları veya ailesinde tiroid otoimmünite öyküsü olan hastalarda daha yüksektir ${ }^{4,5}$. Hipertiroidi, çeşitli vücut sistemlerinde homeostatik dengede bozukluklara neden olabilir ve bu durum kardiyovasküler hastalıklara (KVH) yakalanma riskini arttırmaktadır. Otoimmün tiroid hastalı̆̆ olan bireylerde kardiyovasküler hastalıkların ve diğer otoimmün hastalıkların ortaya çıkma riskinin daha yüksek olduğu yapılan çalışmalarda gösterilmiştir6́.

Kardiyovasküler hastalıklar dünya çapında morbidite ve mortalitenin önde gelen nedeni olmuştur7. KVH'nın artan prevalansı göz önüne alındığında, gelecekte bu hastalıkları öngörebilmek için kullanılabilecek belirteçlerin önemi bir kez daha dikkat çekmektedir. Trombositler, KVH'nın ana patolojik değişikliği ve primer nedeni olan aterotrombozda önemli bir rol oynamaktadır ${ }^{8}$. Nükleusu bulunmayan ve kemik iliğinde megakaryositlerden oluşan trombositlerin; koagülasyon, inflamasyon, otoimmünite ve aterosklerozis gibi süreçlerde etkin rol oynar9,10. Trombositlerin çeşitli fonksiyonları gerçekleştirebilmesi için en önemli basamak aktive olmalarıdır. Aktive olan trombositlerin, büyüklükleri (volümleri) artmaya başlar. Büyük trombositlerin, içeriğinde protrombik faktörlerin ve vazoaktif maddelerin miktarındaki artıştan dolayı enzimatik ve metabolik olarak daha aktif olduğu bilinmektedir ${ }^{11,12}$. Tam kan sayım analizlerinde rutin olarak ölçülen trombosit sayısı (PLT), 
ortalama trombosit hacmi (MPV) ve trombosit dağılım genişliği (PDW), periferik trombositlerin miktarını ve boyut dağılımını yansitan parametrelerdir ${ }^{13}$. Ayrıca MPV ve PDW trombositlerin aktivasyonu ve fonksiyonlarını gösteren önemli parametrelerdir ${ }^{11}$. Yüksek MPV düzeylerinin serebrovasküler ve kardiyovasküler hastalıklarla ilişkili olduğu yapılan çalışmalarla gösterilmiştiriri,15. Trombosit indekslerinden MPV ve PDW, KVH'da potansiyel bir biyobelirteç olarak kabul edilmektedir ${ }^{16}$.

Yüksek platelet indeksleri ile iskemik, aterosklerotik ve tromboembolik kardiyovasküler olaylar arasında güçlü bir ilişkinin olduğu önceki çalışmalarla gösterilmiştir ${ }^{15,17}$. Ayrıca hipertiroidinin vücut sistemlerini etkileyerek kardiyovasküler hastalıklara yatkınlığı arttırdığı da yapılan araştırmalarda gösterilmiștir ${ }^{6}$. Bu çalışmada Graves hastalarında KVH risk değerlendirilmesinde trombosit indekslerinin rolü araștırıldı.

\section{YÖNTEMLER}

\section{Çalışma Grubu}

Aralık 2017 ile Mayıs 2019 tarihleri arasında Harran Üniversitesi Araştırma ve Uygulama Hastanesi Endokrinoloji Polikliniğine başvurmuş sekonder herhangi bir hastalığ hipertiroidi tanısı almış 33 hasta (ortanca yaș = $34,00(16,50)$ yll) ile cinsiyet, yaş ve vücut kitle indeksi (VKI) benzer 37 sağlıklı bireyin (ortanca yaş $=35,00(26,50)$ yll $)$ verisi çalışmaya dahil edilmiştir. Graves hastalığı tanısı, klinik bulgular, düşük tiroid uyarıcı hormon (TSH), yüksek FT3 ve yüksek FT4 seviyelerine göre bir endokrin uzmanı tarafindan konmuş ve sintigrafi ile doğrulanmıștır. Rutin biyokimya laboratuvarında kan sayım analizörü (Abbott Cell-Dyn Ruby Hematology Analyzer, ABD) ile çalışılmış olan trombosit indeksleri ve hormon analizörü (Siemens Centaur XP, ABD) ile çalışılmış olan tiroid fonksiyon parametrelerine ait veriler hasta dosyalarından elde edilmiștir. Ayrıca akut veya kronik sistemik ve enfeksiyöz hastalıkları, düzenli ilaç veya vitamin tüketimi, antioksidan madde kullanımı veya sigara veya alkol tüketimi olan kişiler çalışma dışı bırakıldı. Bu çalışma Harran Üniversitesi Girişimsel Olmayan Klinik Araştırmalar Etik Kurul tarafından onaylandı ve Helsinki Deklarasyonu ve İyi Klinik Uygulama yönergelerine uygun olarak yapıldı (Etik karar no: 17/11/29).

\section{İstatistiksel Analiz}

İstatistiksel analizler SPSS 23.0 (IBM SPSS Inc, Chicago, IL, USA) paket programı ile yapıldı. Verilerin normal dağılımını değerlendirmek için Shapiro Wilk testi kullanıldı. Normal dağılan sayısal değişkenler ortalama \pm standart sapma ve normal dağılım göstermeyen veriler ortanca (çeyrekler açıklı̆ı) olarak ifade edildi. Kategorik değişkenler sayı (n) olarak verildi. İkili grupların karşılaştırılmasında bağımsız Student $t$ testi ve Mann Whitney U testi kullanıldı. Kategorik değişkenleri karşılaştırmak için Chi-square testi kullanıldı. Trombosit indekslerinin tanısal özelliklerini değerlendirmek için Receiver Operating Characteristic (ROC) analizi kullanıldı. Analizlerde güven aralı̆̆ı (CI) \% 95 olarak kabul edildi. $\mathrm{p}<0,05$ istatistiksel olarak anlamlı kabul edildi.

\section{BULGULAR}

Graves hastaları ile kontrol grubuna ait demografik verileri gösteren bilgiler Tablo 1'de özetlenmiştir. $\mathrm{Bu}$ çalışmaya 33 Graves hipertiroidili hasta ve herhangi bir hastalığı bulunmayan 37 sağlıklı kontrol olmak üzere toplam 70 yetişkin birey dahil edildi. Her iki grup arasında yaş, cinsiyet ve VKI açısından istatistiksel olarak anlamlı herhangi bir fark bulunmamaktadır (sırasıyla; $\mathrm{p}=0,487 ; \mathrm{p}=$ $0,532 ; p=0,485)$.

Tablo I: Graves hastaları ile kontrol grubu arasında demografik verilerin karşılaştırılması

\begin{tabular}{|c|c|c|c|}
\hline Veriler & $\begin{array}{c}\text { Graves Grubu } \\
(n=33)\end{array}$ & $\begin{array}{l}\text { Kontrol Grubu } \\
\quad(n=37)\end{array}$ & $p$ - Değerleri \\
\hline Yaş (yil) & $34,00(16,50)$ & $35,00(26,50)$ & $=0,487$ \\
\hline VKİ $\left(\mathrm{kg} / \mathrm{m}^{2}\right)$ & $24,63 \pm 2,50$ & $24,27 \pm 1,75$ & $=0,485$ \\
\hline $\begin{array}{ll}\text { Cinsiyet } & \text { (n) } \\
\text { (kadın/erkek) }\end{array}$ & $19 / 14$ & $14 / 13$ & $=0,532$ \\
\hline
\end{tabular}

Normal dağılım gösteren veriler ortalama \pm standart sapma olarak, normal dağılım göstermeyen veriler ortanca (çeyrekler açıklığı) şeklinde ifade edildi. VKİ: Vücut kitle indeksi 
Graves hastaları ve kontrol grubuna ait trombosit indeksleri ve tiroid fonksiyon testleri ise Tablo 2'de gösterilmiştir. $\mathrm{Bu}$ verilere göre tiroid fonksiyon testlerinden; TSH düzeyleri Graves hastalarında kontrol grubuna kıyasla düşük ve istatistiksel olarak anlamlı bulunmuş olup $(\mathrm{p}<0,001)$, serbest triiyodotironin (fT3) ve serbest tiroksin (fT4) düzeyleri ise Graves hastalarında kontrol grubuna klyasla anlamlı olarak yüksek bulunmuştur $(\mathrm{p}<0,001)$. Her iki çalışma grubu trombosit indeksleri üzerinden karşılaştırıldığında; Graves hastaları ile kontrol grupları arasında; PLT ve trombosit yüzdesi (PCT) bakımından anlamlı herhangi bir fark bulunmazken (sırasıyla; $p=0,202$; $\mathrm{p}=$ 0,289), MPV ve PDW değerleri Graves hastalarında kontrol grubuna göre yüksek olup istatistiksel olarak anlaml fark bulunmaktadır (sırasıyla; $p<0,001 ; p=0,015$ ). Ayrıca Tablo 3'te de gösterildiği gibi Graves hastalarında MPV ve PDW ile fT3 arasında anlamlı pozitif ilişki saptanmıştır (sirasiyla; $r=0,505 ; p=0,003$ ve $r=0,366 ; p=0,036$ ).

Tablo II: Graves hastaları ile kontrol grubuna ait trombosit indeksleri ve tiroid fonksiyon testlerinin karşılaştırılması

\begin{tabular}{|c|c|c|c|}
\hline Veriler & $\begin{array}{c}\text { Graves grubu } \\
\qquad(n=33)\end{array}$ & $\begin{array}{c}\text { Kontrol grubu } \\
\quad(n=37)\end{array}$ & $p$-Değerleri \\
\hline TSH $(\mu \mathrm{IU} / \mathrm{mL})$ & $0,010(0,08)$ & $1,94(1,01)$ & $<0,001$ \\
\hline fT3 (pg/mL) & $6,86(3,54)$ & $3,12(0,49)$ & $<0,001$ \\
\hline fT4 (ng/dL) & $2,29(1,90)$ & $1,06(0,22)$ & $<0,001$ \\
\hline $\operatorname{PLT}\left(\times 10^{3} / \mu \mathrm{L}\right)$ & $267,0(92,95)$ & $286,4(67,20)$ & $=0,202$ \\
\hline РСТ (\%) & $0,224 \pm 0,054$ & $0,212 \pm 0,041$ & $=0,289$ \\
\hline MPV (fL) & $8,59(1,72)$ & $7,26(1,33)$ & $<0,001$ \\
\hline PDW (fL) & $19,99 \pm 0,95$ & $19,47 \pm 0,78$ & $=0,015$ \\
\hline
\end{tabular}

Normal dağılım gösteren veriler ortalama \pm standart sapma olarak, normal dağılım göstermeyen veriler ortanca (çeyrekler açıklığı) şeklinde ifade edildi. fT3: Serbest triiyodotironin, fT4: Serbest tiroksin, MPV: Ortalama trombosit hacmi, PLT: Trombosit sayısl, PCT: Trombosit yüzdesi, PDW: Trombosit dağılım geniş̧liği, TSH: Tiroid uyarıcı hormon

Tablo III: Graves hastalarında fT3 ile MPV ve PDW arasındaki ilişki

\begin{tabular}{|cccc|}
\hline & & MPV & PDW \\
\hline \multirow{2}{*}{$\mathbf{f T 3}$} & $\boldsymbol{r}$ & 0,505 & 0,366 \\
& $\boldsymbol{p}$ & 0,003 & 0,036 \\
& & & \\
\hline
\end{tabular}

fT3: Serbest triiyodotironin, MPV: Ortalama trombosit hacmi, PDW: Trombosit dağılım genişliği
Tablo IV: Graves hastalığında KVH'yı öngörmede MPV ve PDW parametrelerinin ROC eğrisi değerleri.

\begin{tabular}{|lccccc|}
\hline Veriler & $\begin{array}{c}\text { Eğri } \\
\text { Altındaki } \\
\text { Alan }\end{array}$ & $\begin{array}{c}\text { Kesim } \\
\text { Noktasi }\end{array}$ & $\begin{array}{c}\text { Sensitivite } \\
\text { (\%) }\end{array}$ & $\begin{array}{c}\text { Spesifite } \\
\text { (\%) }\end{array}$ & $\begin{array}{c}p \text { - } \\
\text { Değerleri }\end{array}$ \\
\hline $\begin{array}{l}\text { MPV } \\
\text { (fL) }\end{array}$ & 0,747 & 7,65 & 72 & 73 & $<0,001$ \\
PDW & & & & & \\
(fL) & 0,658 & 19,8 & 64 & 70 & $=0,023$ \\
\hline
\end{tabular}

Graves hastalığında KVH'yı öngörmede kullanılan MPV ve PDW parametrelerinin değerlendirilmesi için ROC analizi yapıldı. Kesim noktaları ve eğri altındaki alan Tablo 4 ve Şekil 1'de gösterildiği gibi hesaplandı. MPV için kesim noktası değeri 7,65 fL olarak (sensitivite: $\% 72$, spesifite: \%73, eğri altındaki alan 0,747, p<0.001) PDW için kesim noktası değeri ise 19,8 fL olarak (sensitivite: \%64, spesifite: \%70, eğri altındaki alan $0,658, p=0,023$ ) bulundu.

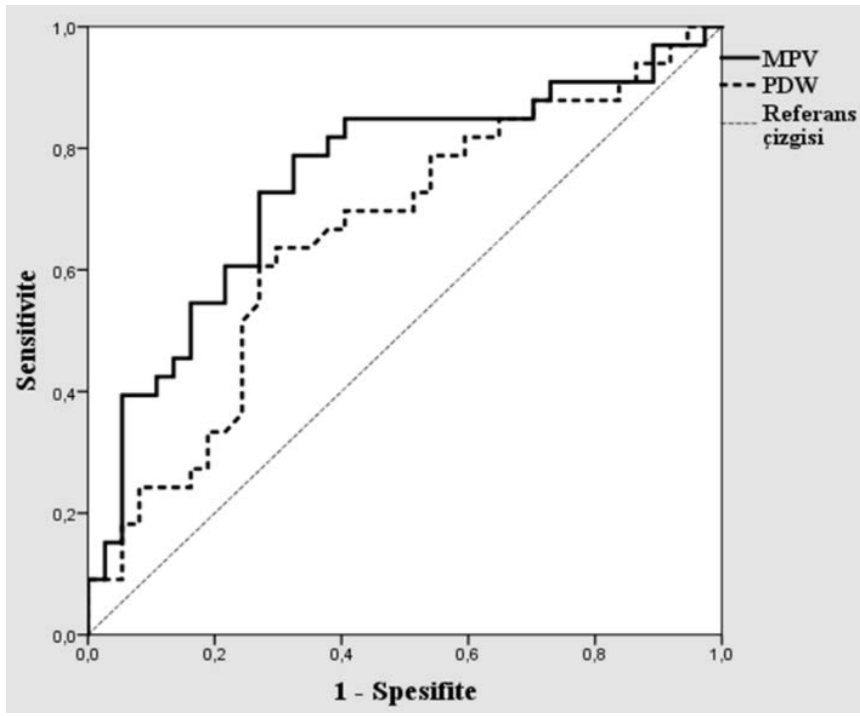

Şekil 1. Graves hastalığında KVH'ları öngörmede MPV ve PDW parametrelerinin ROC eğrisi.

\section{TARTIŞMA}

Gelişmiş ülkelerde en sık görülen hipertiroidi nedeni olarak belirtilen Graves hastalığının trombosit indeksleri ile ilişkisini değerlendiren çalışmaların sayısı literatür taramalarında gördügümüz kadarıla oldukça azdır. Trombosit indekslerinin ölçümünün nispeten kolay ve ucuz olması ve ayrica bu parametrelerin KVH'nın biyobelirteci olma 
potansiyelini güçlendiren çalışmaların her geçen gün çoğalması bu parametrelerin önemini arttırmaktadır. Graves hastalarının KVH'ya yakalanma riskinin trombosit indeksleri aracılığıyla değerlendiren çalışmalara literatürde rastlanılmamıştır. Çalışmamızın temel hipotezi; hipertiroidinin tüm sistemleri etkileyebilme potansiyeli düşünüldüğünde Graves hastalarının $\mathrm{KVH}$ açısından riskli olabileceği ve bu durumun özellikle MPV ve PDW değerleri ile ilişkisinin olabileceğidir. Bu çalışma sonunda elde edilen verilere göre; MPV ve PDW değerleri Graves hastalarında kontrol grubuna göre istatistiksel olarak yüksek bulunmuş, ayrıca Graves hastalarında MPV ve PDW ile fT3 arasinda anlamlı pozitif korelasyon saptanmıștır. Bununla birlikte ROC analizinin sonuçlarıyla beraber tüm veriler hipotezimizin doğruluğunu desteklemektedir.

Yapılan literatür araştırmalarında birçok çalışma, yüksek MPV ile artmış kardiyovasküler olaylar arasında önemli bir ilişki olduğunu göstermiştir ${ }^{15,18,19}$. Shiqi He ve arkadaşlarının ${ }^{20}$ yaptığı çalışmada düşük MPV seviyelerinin KVH ve kalp krizi risklerinin düşüklüğüyle anlamlı bir şekilde ilişkili olduğu rapor edilmiştir. Buna benzer bir şekilde Maluf ve arkadaşlarının ${ }^{21}$ yaptığı kohort çalışmada; MPV'nin artmasının KVH risk artışıyla ilişkili olduğu bildirilmişstir. MPV ve KVH arasındaki pozitif ilişkiyi tasdik eden başka birçok çalışmanın bulunması, MPV'nin KVH için prognostik biyobelirteç olabilme ihtimalini güçlendirmektedir ${ }^{15,22-24}$. Kalp, tiroid hormonunun etkisine duyarlı bir organdır ve kalp performansındaki ölçülebilir değişiklikler, tiroid hormonunun serum konsantrasyonlarındaki küçük değişikliklerle tespit edilir. Tiroid hormonunun, kardiyovasküler hemodinamiği değiștirebilecek etkilere sahip olması, hipertiroidili hastaların kardiyovasküler komplikasyonlara yakalanma riskini arttırmaktadır 25 .
Graves hastalığının trombositler üzerine etkisini araştıran farklı çalışmalara bakıldığında; Marta ve arkadaşları ${ }^{26}$ Graves hastalığının gelişim evresinde, kan trombositlerinin sayısının ve ömrünün azaldığı ifade etmektedir. Bir başka çalışmada ise Graves hastalarının PCT değerlerinin kontrol grubuna klyasla anlamlı olarak daha yüksek olduğu bulunmuştur ${ }^{27}$. Bununla birlikte, hipertiroidizm tedavisinin trombosit sağkalımını hızla iyileştirebileceğine ve trombosit sayısını artırabildiğine dair göstergeler vardır ${ }^{28}$. Bizim çalışmamızda ise Graves hastaları ile kontrol grubu arasinda PLT ve PCT bakımından istatistiksel olarak anlamlı fark olmadığı bulunmuştur. $\mathrm{Bu}$ durumun çalışmamızdaki hasta popülasyonu ile diğer çalışmalardaki hasta popülasyonlarının, hastalı̆̆ın farklı evrelerinde olmasından kaynaklandığını düşünmekteyiz.

Trombosit-lökosit etkileşiminin inflamasyondaki önemli rolünü gösteren pek çok çalışma rapor edilmiştir. Otoantikorlar, kan trombositleri dahil olmak üzere birçok farklı hücrede hedef antijenlerle reaksiyona girer ve otoimmün reaksiyonlar, kan trombositleri ve lenfositlerin karşlıklı işbirliği ile düzenlenir ${ }^{29}$. İnflamasyon ve MPV arasındaki pozitif ilişki daha önceki çalışmalarda gösterilmiştir 9,14 . Literatürdeki bu bilgi akla şu soruyu getirmektedir. Acaba Graves hastalarındaki MPV düzeyindeki artış otoimmün reaksiyonlar sonucunda ml gerçekleşmektedir? Bagir ve arkadaşları $^{30}$ yaptığı çalışmada Graves hastalarında, hastalığın farklı dönemlerinde ve tedavi öncesi ve tedavi sonrası gruplarda MPV düzeylerini ölçmüşler ve sonuç olarak MPV'deki artışa otoimmüniteden ziyade hipertiroidinin katkı sağladığı kanaatine varmışlardır. Benzer şekilde bir başka çalışmada da hipertiroidili Graves olgularında MPV düzeyleri anlamlı derecede yüksek bulunmuş ve bu bulgunun hipermetabolizmaya bağlı olabileceği bildirilmiştir ${ }^{31}$. Sonuç olarak, bu çalışmalar 
bizim bulgularımızı destekler nitelikte olup hipertiroidi sonucu oluşan yüksek MPV düzeyine vurgu yapmaktadır. Çalışmamızda KVH'nın potansiyel biyobelirteci olarak kabul edilen MPV ve PDW'nin Graves hastalarında kontrol grubuna göre anlamlı olarak yüksek çıkması bu hastalarda KVH'ya yakalanma riskinin yüksek olabileceğini düşündürmektedir. İlaveten, ROC analizleri ile özellikle MPV'nin 7,65 gibi bir kesme değerinde \%72 duyarlılık ve \%73 özgüllük ile KVH risk değerlendirmesi için önemli prediktif değere sahip olduğu tespit edilmiștir.

Sonuç olarak, Graves hastalarında MPV ve PDW değerlerinin $\mathrm{KVH}$ risk değerlendirmesinde ve karar vermede önemli bir rolünün olduğu, bu bakımdan korunma stratejileri için kritik bir gösterge olabileceği kanaatindeyiz.

\section{Sinırlılıklar}

$\mathrm{Bu}$ çalışmada hasta sayısının nispeten az olması ve retrospektif bir çalışma olması çalışmanın sınırılıklarını oluşturmaktadır. Daha çok gönüllünün katıldığı, ileriye dönük kohort çalışmaların yapılmasının bu alanda daha net bilgiler ortaya çıkaracağı kanaatindeyiz.

Etik Kurul Kararı: Bu çalışma Harran Üniversitesi Girişimsel Olmayan Klinik Araştırmalar Etik Kurul tarafından onaylandı ve Helsinki Deklarasyonu ve İyi Klinik Uygulama yönergelerine uygun olarak yapıldı (Etik karar no: 17/11/29).

Çıkar Çatışması Beyanı: Yazarlar çıkar çatışması olmadığını bildirmişlerdir.

Finansal Destek: Bu çalışma her hangi bir fon tarafından desteklenmemiştir.

Declaration of Conflicting Interests: The authors declare that they have no conflict of interest.

Financial Disclosure: No financial support was received.

\section{KAYNAKLAR}

1. Saxena P, Charpin-El Hamri G, Folcher M, Zulewski $\mathrm{H}$, Fussenegger M. Synthetic gene network restoring endogenous pituitary-thyroid feedback control in experimental Graves' disease. Proceedings of the National Academy of Sciences. 2016; 113: 1244-9.

2. Gökçay CA, Erdoğan MF. Graves Hastalığı ve Tedavi Stratejileri. Turkiye Klinikleri J EndocrinSpecial Topics. 2014; 7: 41-7.

3. Boelaert K, Torlinska B, Holder RL, Franklyn JA. Older subjects with hyperthyroidism present with a paucity of symptoms and signs: A large crosssectional study. Journal of Clinical Endocrinology and Metabolism. 2010; 95: 2715-26.

4. Taylor PN, Albrecht D, Scholz A, et al. Global epidemiology of hyperthyroidism and hypothyroidism. Nature Reviews Endocrinology. 2018; 14: 301-16.

5. Manji N, Carr-Smith JD, Boelaert K, et al. Influences of age, gender, smoking, and family history on autoimmune thyroid disease phenotype. Journal of Clinical Endocrinology and Metabolism. 2006; 91: 4873-80.

6. Cordiano I, Betterle C, Spadaccino CA, et al. Autoimmune thrombocytopenia (AITP) and thyroid autoimmune disease (TAD): overlapping syndromes?. Clin Exp Immunol. 1998; 113: 373-8.

7.

http://www.who.int/mediacentre/factsheets/\%0A fs317/en/. Accessed July 25, 2019. World Healty Organization.

8. Lusis AJ. Atheroclerosis. Nature. 2000; 407: 233241. doi:10.1038/35025203

9. Franco AT, Corken A, Ware J. Platelets at the interface of thrombosis, inflammation, and cancer. Blood. 2015; 126: 582-8.

10. Morrell CN, Aggrey AA, Chapman LM, Modjeski KL. Emerging roles for platelets as immune and inflammatory cells. Blood. 2014; 123: 2759-67.

11. Brækkan SK, Mathiesen EB, NjøLstad I, et al. Mean platelet volume is a risk factor for venous thromboembolism: The Troms $\varnothing$ study. Journal of Thrombosis and Haemostasis. 2010; 8: 157-62.

12. Huczek Z, Filipiak KJ, Kochman J, et al. Baseline platelet size is increased in patients with acute coronary syndromes developing early stent thrombosis and predicts future residual platelet 
reactivity. A case-control study. Thrombosis Research. 2010; 125: 406-12.

13. Tsiara S, Elisaf M, Jagroop IA, Mikhailidis DP. Platelets as predictors of vascular risk: is there a practical index of platelet activity?. Clin Appl Thrombosis/Hemostasis. 2003; 9: 177-90.

14. Gasparyan AY, Ayvazyan L, Mikhailidis DP, Kitas G. Mean Platelet Volume: A Link Between Thrombosis and Inflammation?. Current Pharmaceutical Design. 2011; 17: 47-58.

15. Vizioli L, Muscari S, Muscari A. The relationship of mean platelet volume with the risk and prognosis of cardiovascular diseases. International journal of clinical practice. 2009; 63: 1509-15.

16. Mirzaie AZ, Abolhasani M, Ahmadinejad B, Panahi M. Platelet count and MPV, routinely measured but ignored parameters used in conjunction with the diagnosis of acute coronary syndrome: single study center in Iranian population, 2010. Medical journal of the Islamic Republic of Iran. 2012; 26: 17-21.

17. Batista TR, Figueiredo RC de, Rios DRA. Platelets volume indexes and cardiovascular risk factors. Revista da Associação Médica Brasileira. 2018; 64: 554-9. doi:10.1590/1806-9282.64.06.554

18. Endler G, Klimesch A, Sunder-Plassmann H, et al. Mean platelet volume is an independent risk factor for myocardial infarction but not for coronary artery disease. British Journal of Haematology. 2002; 117: 399-404.

19. Bath P, Algert C, Chapman N, Neal B. Association of Mean Platelet Volume with Risk of Stroke among 3134 Individuals with History of Cerebrovascular Disease. Stroke. 2004; 35: 622-6.

20. He S, Lei W, Li J, et al. Relation of Platelet Parameters With Incident Cardiovascular Disease (The Dongfeng-Tongji Cohort Study). American Journal of Cardiology. 2019; 123: 239-48.

21. Maluf CB, Barreto SM, Dos Reis RCP, Vidigal PG. Platelet volume is associated with the Framingham risk score for cardiovascular disease in the Brazilian Longitudinal Study of Adult Health (ELSA-Brasil). Clinical Chemistry and Laboratory Medicine. 2016; 54: 879-87. doi:10.1515/cclm-2015-0686
22. Choi DH, Kang SH, Song H. Mean platelet volume: A potential biomarker of the risk and prognosis of heart disease. Korean Journal of Internal Medicine. 2016; 31: 1009-17. doi:10.3904/kjim.2016.078

23. Sansanayudh N, Anothaisintawee T, Muntham D, et al. Mean platelet volume and coronary artery disease: A systematic review and meta-analysis. International Journal of Cardiology. 2014; 175: 43340. doi:10.1016/j.ijcard.2014.06.028

24. Sansanayudh N, Numthavaj P, Muntham D, et al. Prognostic effect of mean platelet volume in patients with coronary artery disease. A systematic review and meta-analysis. Thrombosis and haemostasis. 2015; 114: 1299-1309.

25. Fadel BM, Ellahham S, Ringel MD, et al. Hyperthyroid heart disease. Clinical Cardiology. 2000; 23: 402-8. doi:10.1002/clc.4960230605

26. Marta GN, Campos FPF de. Immune thrombocytopenia and autoimmune thyroid disease: A Controversial Overlap. Autopsy and Case Reports. 2015; 5: 45-8. doi:10.4322/acr.2015.002

27. Yildiz S, Eker E. Platelet indices in graves disease, especially plateletcrit. Medicine Science. 2020; 9: 338-42.

28. McLachlan SM, Rapoport B. Thyrotropinblocking autoantibodies and thyroid-stimulating autoantibodies: Potential mechanisms involved in the pendulum swinging from hypothyroidism to hyperthyroidism or vice versa. Thyroid. 2013; 23 : 14-24. doi:10.1089/thy.2012.0374

29. Tomczynska M, Saluk-Bijak J. The mutual cooperation of blood platelets and lymphocytes in the development of autoimmune thyroid diseases. Acta Biochimica Polonica. 2018; 65: 17-24. doi:10.18388/abp.2017_2321

30. Bagir GS, Haydardedeoglu FE, Bakiner OS, Bozkirli E, Ertorer ME. Mean platelet volume in Graves' disease: A sign of hypermetabolism rather than autoimmunity?. Pakistan Journal of Medical Sciences. 2017; 33: 871-5. doi:10.12669/pjms.334.12659

31. Simsek GB, Ertörer M. Higher mean platelet volume is accompanied with hyperthyroidism in patients with Graves' disease. Cukurova Medical Journal. 2020; 45: 181-5. 